\title{
The Metabolic Elicitors of the Pseudomonas fluorescens N 21.4 Strain as Effective Biotechnological Inoculants for the Cultivation of Blackberry ${ }^{\dagger}$
}

\author{
Helena Martin-Rivilla *, Ana Garcia-Villaraco, Beatriz Ramos-Solano and \\ F. Javier Gutierrez-Manero and José A. Lucas
}

Plant Physiology, Pharmaceutical and Health Sciences Department, Faculty of Pharmacy, Universidad San Pablo-CEU Universities, 28668 Boadilla del Monte (Madrid), Spain

* Correspondence: hel.martin.ce@ceindo.ceu.es; Tel.:+34-913-72-47-85

+ Presented at the 1st International Electronic Conference on Plant Science, 1-15 December 2020.

Published: 30 November 2020

\begin{abstract}
The current need to provide sufficient and quality food to a growing population is linked to the development of new agricultural techniques based on improving crop resistance against stress. Since the consumption of blackberry is becoming very popular for its benefits on human health and it is a crop with a lack of specific inoculants able to boost plant resistance, we looked for an efficient, affordable, and sustainable biotechnological inoculant made of metabolic elicitor molecules of the beneficial rhizobacterium Pseudomonas fluorescens N 21.4 to get a more stress-resilient crop. For this, we inoculated the live rhizobacterium as positive control, since its capacity to elicit blackberry secondary defensive metabolism has been previously demonstrated, and its metabolic elicitors to commercial cultivars of blackberry (Rubus cv. Loch Ness). We measured stress markers such as photosynthetic parameters, but also pathogenesis-related proteins and polyphenolic composition of the leaves, and the bioactive content of the fruit in two stages of ripening. Our results showed that the metabolic elicitor-inoculated plants were more prepared to cope with stress since higher values of photosynthesis were observed, as well as an activation of the pathogenesis-related proteins. Furthermore, the leaves and the fruits of the inoculated plants showed an enhancement in the concentration of beneficial polyphenols, highlighting the increase in epicatechin and kaempferol. This would mean having better quality fruits and would revalorize the leaves pruning as a potential source of polyphenols, providing added value to the crop while following the premises of the circular economy.
\end{abstract}

Keywords: blackberry; Pseudomonas fluorescens N 21.4; metabolic elicitors; secondary defensive metabolism; circular economy; epicatechin

\section{Introduction}

A continuously growing population linked to the current aim to reach food security (access to sufficient, safe and nutritious food), requires technological and biotechnological advance, being the improvement of crops a priority to achieve this objective. Predictions have advised that the world would need to increase crop production by 26-68\% from 2014 baseline levels [1]; therefore, this pressure imposed in the agrifood industry has favoured the development of new agricultural techniques aimed at achieving sufficient and quality food, always within the framework of sustainable production.

The greatest handicap that agricultural production has to face is the material and economic losses due to pests and adverse conditions of abiotic stress [2], and this is why looking for stressresilient crops has become an essential priority for research. Consequently, it is vital that agricultural techniques be focused on the protection of crops against biotic and abiotic stress and be based on the study of plant physiology, plant immune system, as well as on plant interactions with pathogens or with beneficial microorganisms. 
The blackberry crop is relatively recent; however, the consumption of these fruits has exponentially grown in the market in the last decade due to their proven nutraceutical potential $[3,4]$. This increase in consumption means that blackberry crop new intensive production systems, to improve the quality and sustainability of this cultivation, are needed. The implementation of specific inoculants able to boost blackberry plants resistance is also necessary.

For all the above mentioned, the aim of our work was to improve the secondary defensive metabolism of blackberry cultivated plants (Rubus cv. Loch Ness) and their resistance to stress to obtain a better and sustainable yield, with leaves and fruits richer in usable polyphenols, through the inoculation of the metabolic elicitors (ME) of the beneficial rhizobacterium P. fluorescens N 21. 4. Our results showed that ME-based inoculants would be effective and convenient since the leaves and the fruits of the inoculated plants showed higher amount of beneficial compounds and the plants were more prepared to cope with stress. This way, an efficient, affordable, and environmentally friendly biotechnological inoculant to get a more stress-resilient crop would be settled. This inoculant would be providing higher quality fruit and usable leaves, while it also would be contributing to reach food security and to fulfil the premises of the circular economy.

\section{Experiments (Methods)}

\subsection{Blackberry Experimental Design}

The Rubus cv. Loch Ness plants of this work were provided by Agricola El Bosque S.L. "La Canastita" (Lucena del Puerto, Huelva, Spain). Plants were grown in Huelva from November 2017 to April 2018, following the usual agricultural prodedures [5]. The experiment consisted of 540 plants, organized in five greenhouses, each with two lines with 120 plants in total, each line being one replicate (60 plants). Three of the lines were inoculated with the strain P. fluorescens N 21.4 at root level, other three lines with the ME of $\mathrm{N} 21.4$ by aerial spraying, and other three lines were left as non-inoculated controls.

Leaves and fruits were sampled in April 2018, when red and black fruits were present at the same time, and frozen in liquid nitrogen. Three replicates were taken, being each one constituted from $125 \mathrm{~g}$ of fruits and leaves of 60 plants.

\subsection{Bacterial Experimental Design}

The bacterial strain of this work was P. fluorescens N 21.4 (Spanish Type Culture Collection accession number CECT 7620), a Gram-negative bacilli isolated from the rhizosphere of Nicotiana glauca Graham [6]. This rhizobacterium is able to improve blackberry fruit yield and quality by increasing flavonoid content $[4,7,8]$.

The strain was stored at $-80{ }^{\circ} \mathrm{C}$ in nutrient broth (CONDA) with $20 \%$ glycerol. Inoculum was prepared by streaking the strain onto PCA (CONDA) plates $\left(28^{\circ} \mathrm{C}\right.$ for $24 \mathrm{~h}$ ), and then passing bacterial cells into sterile nutrient broth $\left(180 \mathrm{rpm}\right.$ of agitation) at $28^{\circ} \mathrm{C}$ for $24 \mathrm{~h}$ to obtain a $10^{9} \mathrm{cfu} \mathrm{mL}$ inoculum. Inoculum was then diluted from $10^{9}$ to $10^{7} \mathrm{cfu} \mathrm{mL}^{-1}$.

Inoculum of ME was prepared by centrifuging a 24 h-grown culture of N 21.4 at $2890 \times g$ during $20 \mathrm{~min}$ at $4{ }^{\circ} \mathrm{C}$. Cells were discarded and the remaining supernatant was diluted as the strain. $\mathrm{N} 21.4$ and ME were inoculated every 15 days during the whole plant cycle ( $0.5 \mathrm{~L}$ of inoculum/ plant).

\subsection{Analysis of Photosynthetic Parameters}

Two photosynthetic parameters (F0 and $\mathrm{Fv} / \mathrm{Fm}$ ) were measured with a pulse amplitude modulated fluorometer (Hansatech FM2, Hansatech, Inc, UK). To determine Fv/Fm ratio, after 30 min of leaf-dark-adaptation, a weak modulated irradiation $\left(1 \mu \mathrm{mol} / \mathrm{m}^{2} \mathrm{~s}^{1}\right)$ was applied to firstly determine minimal fluorescence yield (F0), and a $0.7 \mathrm{~s}$ saturating flash $\left(10000 \mu \mathrm{mol} / \mathrm{m}^{2} \mathrm{~s}^{1}\right)$ was then superimposed to induce the maximum fluorescence yield of chlorophyll (Fm). The Fv variable was calculated as the difference between Fm and F0. The maximum photosynthetic efficiency of the photosystem II (PSII) was therefore calculated as Fv/Fm [9]. 
Total chlorophyll a was also measured by using the formula proposed by Lichtenthaler [10]: Chl $\mathrm{a}\left(\mathrm{mg} \mathrm{g}^{-1}\right.$ Fresh Weigh $)=\left[\left(12.24^{*} \mathrm{Abs} 663 \mathrm{~nm}\right)-\left(2.79^{*} \mathrm{Abs} 647\right)\right]^{*}(\mathrm{~V}(\mathrm{~mL}) / \mathrm{FW}(\mathrm{g}))$ For this, five $\mathrm{mg}$ of the leaves powder were mixed with $2 \mathrm{~mL}$ of $80 \%$ acetone. After $24 \mathrm{~h}$ at $4{ }^{\circ} \mathrm{C}$, the mixture was centrifuged for $10 \mathrm{~min}$ at $2890 \times \mathrm{g}$ at room temperature. The supernatant was collected and absorbance was measured at 663,647 y $470 \mathrm{~nm}$ using a spectrophotometer Biomate 5. All measurements were carried out with the leaves of 3 plants of each treatment in each tunnel.

\subsection{Pathogenesis-Related Proteins (PRs)}

Glucanase (PR2) (EC 3.2.1.6) activity was measured as described by Lee et al. [11]. The reaction consists of $375 \mu \mathrm{L}$ of sodium acetate buffer $50 \mathrm{mM} \mathrm{pH} 5,25 \mu \mathrm{L}$ of laminarina $10 \mathrm{mg} \mathrm{mL}^{-1}$ and $100 \mu \mathrm{L}$ of leaf methanolic extract. After an hour at $37^{\circ} \mathrm{C}, 1.5 \mathrm{~mL}$ of DNS reagent were added. The mixture was heated at $100^{\circ} \mathrm{C}$ during $5 \mathrm{~min}$ and finally, $550 \mathrm{~nm}$ absorbance was measured. A calibration curve was made with glucose in acetate buffer with concentrations between $0.1-1 \mathrm{mg} \mathrm{mL}^{-1}$. Data was expressed as $\mu \mathrm{mol} \mathrm{mg}$ protein ${ }^{-1} \mathrm{~min}^{-1}$.

Chitinase (PR3) (EC 3.2.1.14) activity was measured as described by Lee et al. [11]. The reaction consists of $500 \mu \mathrm{L}$ of sodium acetate $0.1 \mathrm{M} \mathrm{pH} 5.5,1 \%$ colloidal chitin in the buffer and $500 \mu \mathrm{L}$ of leaf methanolic extract. After two hours of incubation at $37^{\circ} \mathrm{C}, 200 \mu \mathrm{L}$ of $1 \mathrm{~N} \mathrm{NaOH}$ were added and it was centrifuged at $10,000 \times g$ for $10 \mathrm{~min}$. The supernatant was mixed with $1 \mathrm{~mL}$ of Schales reagent. The mix was heated at $100{ }^{\circ} \mathrm{C}$ for $15 \mathrm{~min}$ and the absorbance at $420 \mathrm{~nm}$ was measured. A calibration curve was made with $\mathrm{N}$ acetyl glucosamine in sodium acetate buffer at concentrations between 0.01 and $0.1 \mathrm{mg} \mathrm{mL}^{-1}$. Data was expressed as $\mu \mathrm{mol} \mathrm{mg}$ protein $^{-1} \mathrm{~min}^{-1}$.

\subsection{Leaves and Fruits Polyphenolic Characterization by UHPLC/ESI-QTOF-MS}

To measure the polyphenolic composition of blackberry leaves and fruits, $10 \mathrm{mg}$ of lyophilized leaves and fruits were added to $1 \mathrm{~mL}$ of methanol, vortexed for $1 \mathrm{~min}$, sonicated for $5 \mathrm{~min}$, and centrifuged at $2890 \times g$ for 5 min at $4{ }^{\circ} \mathrm{C}$. Supernatants $(2 \mu \mathrm{L})$ were injected on a reversed-phase column (Zorbax Eclipse XDB-C18 $4.6 \times 50 \mathrm{~mm}, 1.8 \mu \mathrm{m}$, Agilent Technologies) at $40{ }^{\circ} \mathrm{C}$ of a 1290 Infinity series UHPLC system associated to an electrospray ionization source (ESI) with Jet Stream technology and 6550 iFunnel QTOF/MS system (Agilent Technologies, Waldbronn, Germany). The flow rate was 0.5 $\mathrm{mL} \mathrm{min}^{-1}$ with a mobile phase consisted of solvent A: $0.1 \%$ formic acid, and solvent B: methanol. Gradient elution consisted of 2\% B (0-6 min), 2-50\% B (6-10 min), 50-95\% B (11-18 min), 95\% B for 2 $\min (18-20 \mathrm{~min})$, and returned to starting conditions $2 \% \mathrm{~B}$ in one $\min (20-21 \mathrm{~min})$ to finally keep the re-equilibration with a total analysis time of $25 \mathrm{~min}$. Each sample was injected twice in six different concentrations to create calibration curves in which sample peak areas were extrapolated. The UHPLC-MS data analysis was performed by MassHunter Qualitative Analysis Software version B.08.00 using Molecular Feature Extraction (MFE). For obtaining of all data, UHPLC/ESI-QTOF-MS (Agilent Technologies) was used.

\section{Results}

\subsection{Photosynthetic Parameters}

The parameters related to plant photosynthetic functioning appear in Figure 1. Figure 1a shows that N 21.4 and ME-treated plants performed significatively lower values of F0 (minimal fluorescence yield) than control plants. There were not statistically significant differences between both bacterial treatments (N 21.4 vs. ME). However, Figure 1b shows significant higher Fv/Fm (PSII maximum photosynthetic efficiency) values in ME-treated plants compared to N 21.4-treated plants and control plants (the lowest value).

Regarding chlorophyll a (Figure 1c), ME-treated plants have significant higher concentration of this pigment than N 21.4-treated plants and control plants, being no significant differences between these two last treatments. 


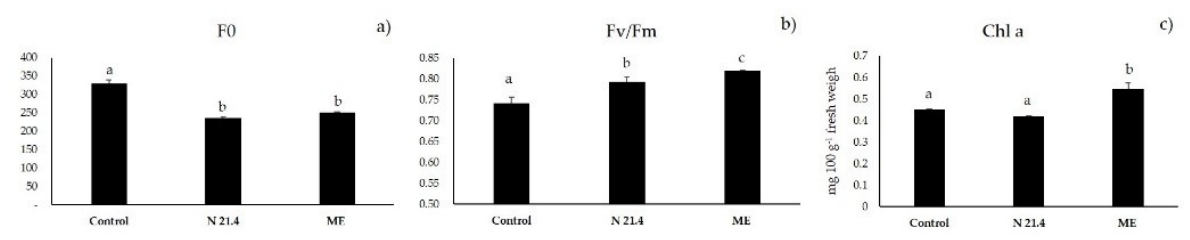

Figure 1. Photosynthetic parameters analysed in blackberry leaves of plants inoculated with $P$. fluorescens N 21.4, with its metabolic elicitors (ME) and in non-inoculated control plants: (a) minimal fluorescence yield (F0); (b) PSII maximum photosynthetic efficiency (Fv/Fm); (c) Chlorophyll a content.

\subsection{Pathogenesis-Related Proteins (PRs)}

Figure 2a,b shows that ME-treated plants expressed higher concentration of both PRs (Glucanase PR2 and Chitinase PR3) than N 21.4-treated plants, which performed even lower values than control plants.
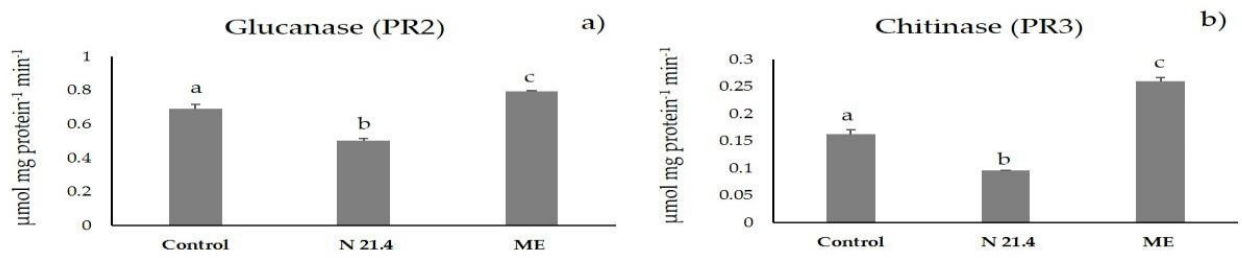

Figure 2. Activity of pathogenesis-related proteins analysed in blackberry leaves of plants inoculated with P. fluorescens N 21.4, with its metabolic elicitors (ME) and in non-inoculated control plants: (a) glucanase (PR2), and (b) Chitinase (PR3).

\subsection{Polyphenololic Composition of Blackberry Leaves and Fruits}

The leaf polyphenolic composition (compounds and concentration $\left(\mu \mathrm{g} \mathrm{g}^{-1}\right)$ ) of control and N 21.4 and ME-treated plants (Rubus cv. Loch Ness) is shown in Table 1. The polyphenolic compounds present in blackberry leaves belongs to the following groups: flavonols, flavones, flavanones, flavanols, hydroxycoumarins, dihydrochalcones and hydroxy benzoic acids. In general, all the compounds of the leaves of plants inoculated with the bacterial treatments (N 21.4, ME) were found in a significantly higher concentration than the compounds of the control plant leaves, highlighting the increase in kaempferol derivatives, in Q 3- O-R, luteolin, aesculetin and salicylic acid. ME treatment compared to live strain $(\mathrm{N}$ 21.4) treatment resulted in a significant increase in $\mathrm{Q} 3-\mathrm{O}-\mathrm{G}$, luteolin, (-)-epicatechin and phloridzin.

Table 1. Leaf polyphenolic composition $\left(\mu \mathrm{g} \mathrm{g}^{-1}\right)$ of control and N 21.4 and ME-treated plants.

\begin{tabular}{ccccc}
\hline & Compound & Control & N 21.4 & ME N 21.4 \\
\hline & Kaempferol 3-O-G & $12.62 \pm 0.77(\mathrm{a})$ & $25.09 \pm 0.185(\mathrm{~b})$ & $24.23 \pm 1.09(\mathrm{~b})$ \\
Flavonols & Kaempferol 3-O-G & $6.82 \pm 0.285(\mathrm{a})$ & $17.2 \pm 0.09(\mathrm{~b})$ & $14.67 \pm 0.69(\mathrm{c})$ \\
& Quercetin 3-O-G & $51.44 \pm 0.4(\mathrm{a})$ & $50.06 \pm 0.05(\mathrm{~b})$ & $56.32 \pm 2.955(\mathrm{c})$ \\
& Quercetin 3-O-R & $16.5 \pm 0.16(\mathrm{a})$ & $22.89 \pm 0.98(\mathrm{~b})$ & $21.19 \pm 0.99(\mathrm{c})$ \\
Flavone & Luteolin & $0.49 \pm 0.01(\mathrm{a})$ & $1.11 \pm 0.095(\mathrm{~b})$ & $1.8 \pm 0.12(\mathrm{c})$ \\
Flavanones & Naringenin & $12.05 \pm 0.05(\mathrm{a})$ & $12.28 \pm 0.035(\mathrm{a})$ & $12.22 \pm 0.07(\mathrm{a})$ \\
Flavanols & $(+)-C a t e c h i n$ & $15.63 \pm 0.42(\mathrm{a})$ & $15.07 \pm 0.295(\mathrm{a})$ & $11.9 \pm 0.3(\mathrm{~b})$ \\
& $(-)$-Epicatechin & $373.11 \pm 3.425(\mathrm{a})$ & $295.37 \pm 0.425(\mathrm{~b})$ & $387 \pm 12.99(\mathrm{c})$ \\
Hydroxycoumarins & Aesculetin & $0.024 \pm 0.001(\mathrm{a})$ & $0.061 \pm 0.005(\mathrm{~b})$ & $0.042 \pm 0.007(\mathrm{c})$ \\
Dihydrochalcone & Phloridzin & $0.64 \pm 0.02(\mathrm{a})$ & $0.43 \pm 0.005(\mathrm{~b})$ & $0.67 \pm 0.015(\mathrm{c})$ \\
Hydroxy benz. acid & Salicylic acid & $9.09 \pm 0.405(\mathrm{a})$ & $11.84 \pm 0.07(\mathrm{~b})$ & $10.44 \pm 0.6(\mathrm{c})$ \\
\hline
\end{tabular}

Different letters $(a, b, c)$ show statistically significant differences between treatments $(p<0.05)$.

The fruit (red and black) polyphenolic composition (main compounds and concentration ( $\mu \mathrm{g}$ $\left.\mathrm{g}^{-1}\right)$ ) of control and N 21.4 and ME-treated plants (Rubus cv. Loch Ness) is shown in Table2. 
Table 2. Polyphenolic composition $\left(\mu \mathrm{g} \mathrm{g}^{-1}\right)$ of red and black fruits of control and N 21.4 and ME-. treated plants (Rubus cv. Loch Ness).

\begin{tabular}{|c|c|c|c|c|c|c|}
\hline \multirow[b]{2}{*}{ Compound } & \multicolumn{2}{|c|}{ Control } & \multicolumn{2}{|c|}{ N 21.4} & \multicolumn{2}{|c|}{ ME } \\
\hline & Red & Black & Red & Black & Red & Black \\
\hline Q-3-O-G & $13.8 \pm 0.3 \mathrm{a}(\mathrm{x})$ & $13.2 \pm 0.1 \mathrm{a}(\alpha \beta)$ & $13.1 \pm 0.55 \mathrm{a}(\mathrm{x})$ & $14.1 \pm 0.3 \mathrm{a}$ & $17.7 \pm 0.3 \mathrm{a}(\mathrm{y})$ & $12.9 \pm 0.4 \mathrm{~b}(\beta)$ \\
\hline Q-3-O-R & $7.5 \pm 0.25 \mathrm{a}(\mathrm{x})$ & $6.2 \pm 0.1 \mathrm{~b}(\alpha)$ & $7.4 \pm 0.35 a(x)$ & $7.6 \pm 0$ & $9.7 \pm 0.25 \mathrm{a}(\mathrm{y})$ & \\
\hline $\mathrm{K}-3-\mathrm{O}-\mathrm{R}$ & $0.661 \pm 0 \mathrm{a}(\mathrm{x})$ & $0.44 \pm 0.01 \mathrm{~b}(\alpha)$ & $0.631 \pm 0.01 \mathrm{a}(\mathrm{x})$ & 0.501 & $0.814 \pm 0.03 \mathrm{a}(\mathrm{y})$ & 0.426 \\
\hline $\mathrm{K}-3-$ & $1.1 \pm 0.05 a(x)$ & $0.8 \pm 0.05 \mathrm{~b}(\alpha)$ & $0.9 \pm 0$ a (y) & $0.8 \pm 0$ & $1.3 \pm 0 \mathrm{a}(\mathrm{z})$ & $0.7 \pm 0$ \\
\hline Epica & $302 \pm 8.3$ a (x) & $226.7 \pm$ & $356 \pm 0$ & $304.4 \pm$ & 386.8 & 247. \\
\hline Cat & $21 \pm$ & $9.5 \pm 0$. & 25.4 & $17.2 \pm$ & (z) & $11.1 \pm$ \\
\hline Phlo & $0.26 \pm 0 \mathrm{a}(\mathrm{x})$ & $0.442 \pm 0.0 \mathrm{~b}(\alpha)$ & $0.216 \pm 0 \mathrm{a}(\mathrm{y})$ & $0.397 \pm c$ & $0.329 \pm 0 \mathrm{a}(\mathrm{z})$ & $0.392 \pm 0 \mathrm{~b}(\beta)$ \\
\hline C-3-O-G & $838 \pm 21$ a $(x)$ & $3162.2 \pm 42.8 \mathrm{~b}(\alpha)$ & $560.7 \pm 18.2 \mathrm{a}(\mathrm{y})$ & $2968.7 \pm 46.3 \mathrm{~b}(\beta)$ & $727.23 \pm 18$ a $(x)$ & $3117.8 \pm 38.4 \mathrm{~b}(\mathrm{c}$ \\
\hline $\begin{array}{l}\text { Chlorogenic } \\
\text { acid }\end{array}$ & $a(x)$ & 0.33 & $0.6 \pm 0.0$ & $\alpha)$ & $x)$ & $(\alpha)$ \\
\hline Luteolin & $0.05 \pm 0.01 \mathrm{a}(\mathrm{x})$ & $0.029 \pm 0 \mathrm{a}(\alpha)$ & $0(\mathrm{y})$ & $0(\alpha)$ & $0.091 \pm 0.02 \mathrm{a}(\mathrm{x})$ & $0 \mathrm{~b}(\alpha)$ \\
\hline
\end{tabular}

Letters $\mathrm{a}$ and $\mathrm{b}$ indicate significant differences between red and black fruit within the same treatment; $x, y$ and $z$ indicate significant differences between treatments in red fruit; and letters $\alpha, \beta, \gamma$ indicate significant differences between treatments in black fruit $(p<0.05)$.

All the compounds present in red fruit performed statistically higher values (1.2-1.6 times) in ME-treated plants than in N 21.4-treated plants. Meanwhile, N 21.4-treated-plants showed similar values to control plants, except for (-)-epicatechin and (+)-catechin that were 1.2 times significantly higher. However, all the compounds present in black fruit (except cyaniding 3-O-G) performed statistically higher values in N 21.4-treated plants (1.1-1.5 times) than in ME-treated plants. Values of ME-treated-plants were similar to control plants, except for (-)-epicatechin and (+)-catechin that were 1.1 times significantly higher.

\section{Discussion}

The necessity to improve crops to provide sufficient and quality food to a continuous growing population, fulfilling the concept of food security, is nowadays linked to the development of new and more efficient and ecofriendly agricultural methods based on improving the resistance of crops against stress by enhancing the plants' immune system. A challenging tool to achieve this goal is the use of biological plant inoculants based on beneficial microorganisms or their derived metabolic molecules [12,13].

This work aimed to present a new plant inoculant, based on inert molecules derived from the metabolism of a beneficial rhizobacterium and capable of boosting the immune system and the resilience of blackberry-cultivated plants; and also to give to the crop an added economic value by obtaining better quality fruits with higher content of polyphenols beneficial to human health and usable leaves as a source for the extraction of these beneficial compounds.

To reach our objectives, we inoculated the live rhizobacterium ( $P$. fluorescens $N$ 21.4) as positive control, since its capacity to elicit blackberry secondary defensive metabolism has been previously demonstrated $[4,7,8]$, and its ME to commercial cultivars of blackberry (Rubus cv. Loch Ness). We measured photosynthetic parameters, pathogenesis-related proteins activity and the polyphenolic composition of the leaves and the fruits in two stages of ripening (red and black).

As the photosynthetic apparatus of plants is very sensitive to stress, it is used as a factor capable of reflecting the general health condition of a plant [14]. Two parameters commonly used to measure photosynthesis performance are F0, (minimum fluorescence yield), and Fv/Fm (maximum photochemical efficiency of PSII). Our results indicated that N 21.4 and especially ME-treated plants had a better photosynthetic performance than control plants and that were less stressed and had etter general fitness. This was due to their lower values of F0 (Figure 1a), since high values means breakdowns in PSII and photosynthesis efficiency loss [15]. Moreover, treated plants and especially ME-treated plants showed higher values of Fv/Fm (maximum capacity of the PSII to transfer electrons to the electron transport chain) than control plants (Figure 1b), being lower values of this parameter indicative of photoinhibition [14]. Therefore, ME-based inoculants would decreased 
photosynthetic damage caused by stress and would suppose a powerful performance of the photosynthetic apparatus, with greater capacity to channel electrons to the electron transport chain and to generate more energy [15].

We also measured the amount of $\mathrm{Chl}$ a since it is the main pigment involved in the absorption of light photons and in the excitation of electrons that pass to the transport chain for generating energy [16]. ME-treated plants showed the highest levels of $\mathrm{Chl}$ a (Figure 1c), which also correlates with the lowest F0 and the highest Fv/Fm values, and which means that ME-treated plants had a photosynthetic system in optimal operating conditions.

Moreover, activity of the PR2 and PR3 were evaluated, since these PRs have a vital role in facing pathogen infection [4]. Our results showed that the activity of both PRs was significantly higher in ME-treated plants than in control or N 21.4-treated plants (Figure 2). This suggests that the ME-based inoculant is able to strengthen plants to overcome pathogen outbreaks. These results were consistent with those of photosynthetic parameters, demonstrating once again that ME-treated plants had a better fitness.

Regarding the amount of polyphenols present in blackberry leaves, it was seen that the concentration of all the bioactives measured was higher in plants treated with both bacterial treatments (Table 1), highlighting the kaempferol and quercetin derivatives, the lutelin, hydroxycoumarin and epicatechin (with the ME). This means that our inoculants are efficient triggering the blackberry secondary metabolism. All these compounds have great antioxidant capacity, and are able to reduce plant oxidative stress by inducing ROS scavenging enzymes. Kaempferol derivatives and (-)-epicatechin have also shown anti-pathogenic capacity against fungi and bacterial infection $[17,18]$. Therefore, inoculated plants, with higher concentration of these antioxidant and anti-pathogenic compounds are more protected to stress than control plants.

Furthermore, kaempferol and (-)-epicatechin-rich foods are linked to a lower risk of various types of cancer [19]. Therefore, the leaves could be used as a source to extract these compounds for food supplements.

The bioactive analysis in the blackberry fruit also revealed that fruits of inoculated plants, and remarkably fruits of ME-inoculated plants, accumulated greater amount of antioxidant polyphenolic compounds than control plants (Table 2). A highlighting point was the sharp increase in (-)epicatechin and (+)-catechin at both stages of ripening with both treatments.

In general, the treatment based on ME had a more noticeable influence on plant elicitation, boosting the amount of the majority of the metabolites of fruits and leaves, these having better nutritional quality. Hence, it can be assumed that ME-treated plants had a stronger secondary defensive metabolism and were more protected against biotic and abiotic stress.

With all of our results we can affirm that, by using plant inoculants based on the ME of the rhizobacterium $P$. fluorescens N 21.4, we got a sustainable blackberry crop, with a very active secondary defensive metabolism, more adapted to cope with stress, and with fruits and leaves richer in beneficial polyphenols.

\section{Conclusions}

The metabolic elicitors of the $P$. fluorescens N 21.4 triggered the secondary defensive metabolism of blackberry (Rubus cv. Loch Ness) plants and improved plant fitness by increasing photosynthesis performance and pathogenesis-related proteins activity, decreasing oxidative stress, and boosting the synthesis of beneficial bioactives accumulated in the leaves and fruits. Therefore, the metabolic elicitors of the P. fluorescens N 21.4 are bio-inoculants perfectly efficient, economically and environmentally convenient alternative to agrochemicals or alternative or complementary to rhizobacteria-based products. They generated a greater economic yield in the blackberry crop by getting fruits with better nutritional qualities and allowing leaves to be used as a source for the extraction of metabolites with beneficial effects on human health, such as epicatechin and kaempferol and quercetins derivatives.

Author Contributions: The results are part of the doctoral thesis of H.M.-R. whose supervisors were J.A.L. and F.J.G.-M; H.M.-R., J.A.L. and B.R.-S designed the experiments performed; H.M.-R. wrote the main manuscript 
and all authors reviewed the manuscript. All authors have read and agreed to the published version of the manuscript.

Acknowledgments: Ministerio de Economía y Competitividad of Spain through the project AGL- 2013-45189R.

Conflicts of Interest: The authors declare no conflict of interest.

\section{Abbreviations}

$\begin{array}{ll}\text { C-3-O-G } & \text { Cyanidin-3-O-Glucoside 252 } \\ \text { Chl a } & \text { Chlorophyll a 253 } \\ \text { FW } & \text { Fresh weigh 254 } \\ \text { K-3-O-G } & \text { Kaempferol 3-O-Glucoside 255 } \\ \text { K-3-O-R } & \text { Kaempferol 3-O-Rutinoside 256 } \\ \text { ME } & \text { Metabolic elicitors 257 } \\ \text { PSII } & \text { Photosystem II 258 } \\ \text { Q-3-O-G } & \text { Quercetin 3-O-Glucoside 259 } \\ \text { Q-3-O-R } & \text { Quercetin 3-O- Rutinoside 260 } \\ \text { PR } & \text { Pathogenesis-Related Protein 261 } \\ \text { UHPLC/ESI- } & \text { Ultra-High Performance Liquid Chromatography/ Electrospray 262 Ionization Source- } \\ \text { QTOF-MS } & \text { Quadrupole Time-of-Flight Mass Spectrometry Analyser }\end{array}$

\section{References}

1. Hunter, M.C.; Smith, R.G.; Schipanski, M.E.; Atwood, L.W.; Mortensen, D.A. Agriculture in 2050: Recalibrating targets for sustainable intensification. Bioscience 2017, 67, 385-390, doi:10.1093/biosci/bix010.

2. Miller, R.; Ge Costa Alves, G.S.; Van Sluys, M.A. Plant immunity: Unravelling the complexity of plant responses to biotic stresses. Ann. Bot. 2017, 119, 681-687, doi:10.1093/aob/mcw284.

3. Feresin, R.G.; Huang, J.; Klarich, D.S.; Zhao, Y.; Pourafshar, S.; Arjmandi, B.H.; Salazar, G. Blackberry, raspberry and black raspberry polyphenol extracts attenuate angiotensin II- induced senescence in vascular smooth muscle cells. Food Funct. 2016, 7, 4175-4187, doi:10.1039/c6fo00743k.

4. Martin-Rivilla, H.; Garcia-Villaraco, A.; Ramos-Solano, B.; Gutierrez-Manero, F.J.; Lucas, J.A. Improving flavonoid metabolismin blackberry leaves and plant fitness by using the bioeffector Pseudomonas fluorescens N 21.4 and its metabolic elicitors: A biotechnological approach for a more sustainable crop. J. Agri. Food Chem. 2020, 68, 6170-6180, doi:10.1021/acs.jafc.0c01169.

5. Ramos-Solano, B.; Garcia-Villaraco, A.; Gutierrez-Manero, F.J.; Lucas, J.A.; Bonilla, A.; Garcia-Seco, D. Annual changes in bioactive contents and production in field-grown blackberry after inoculation with Pseudomonas fluorescens. Plant Physiol. Biochem. 2014, 74, 1-8, doi:10.1016/j.plaphy.2013.10.029.

6. Ramos-Solano, B.; Lucas Garcia, J.A.; Garcia-Villaraco, A.; Algar, E.; Garcia-Cristobal, J.; Gutierrez Manero, F.J. Siderophore and chitinase producing isolates from the rhizosphere of Nicotiana glauca Graham enhance growth and induce systemic resistance in Solanum lycopersicum L. Plant Soil 2010, 334, 189-197, doi:10.1007/s11104-010-0371-9.

7. Garcia-Seco, D.; Zhang, Y.; Gutierrez-Manero, F.J.; Martin, C.; Ramos-Solano, B. Application of Pseudomonas fluorescens to blackberry under field conditions improves fruit quality by modifying flavonoid metabolism. PLoS ONE 2015, 10, 23, doi:10.1371/journal.pone.0142639.

8. Martin-Rivilla, H.; Garcia-Villaraco, A.; Ramos-Solano, B.; Gutierrez-Manero, F.J.; Lucas, J.A. Metabolic elicitors of Pseudomonas fluorescens N 21.4 elicit flavonoid metabolism in blackberry fruit. J. Sci. Food Agri. 2020, (in press), doi:0.1002/jsfa.10632.

9. Ögren, E.; Baker, N.R. Evaluation of a technique for the measurement of chlorophyll fluorescence from leaves exposed to continuous white light. Plant Cell Environ. 1985, 8, 539-547, doi:10.1111/j.13653040.1985.tb01691.x.

10. Lichtenthaler, H.K. Chlorophylls and carotenoids: Pigments of photosynthetic biomembranes. Methods Enzymol. 1987, 148, 350-382, doi:10.1016/0076-6879(87)48036-1.

11. Lee, B.R.; Jung, W.J.; Lee, B.H.; Avice, J.C.; Ourry, A.; Kim, T.H. Kinetics of drought-induced pathogenesis-related proteins and its physiological significance in white clover leaves. Physiol. Plant. 2008, 132, 329-337, doi:10.1111/j.1399-3054.2007.01014.x. 
12. Martin-Rivilla, H.; Garcia-Villaraco, A.; Ramos-Solano, B.; Gutierrez-Manero, F.J.; Lucas, J.A. Extracts from cultures of Pseudomonas fluorescens induce defensive patterns of gene expression and enzyme activity while depressing visible injury and reactive oxygen species in Arabidopsis thaliana challenged with pathogenic Pseudomonas syringae. AoB Plants 2019, 11, 1-9, doi:10.1093/aobpla/plz049.

13. Martin-Rivilla, H.; Gutierrez-Mañero, F.J.; Gradillas, A.; Navarro, M.O.P.; Andrade, G.; Lucas, J.A. Identifying the compounds of the metabolic elicitors of Pseudomonas fluorescens N 21.4 responsible for their ability to induce plant resistance. Plants 2020, 9, 1020, doi:10.3390/plants9081020.

14. Garcia-Cristobal, J.; Garcia-Villaraco, A.; Ramos, B.; Gutierrez-Manero, J.; Lucas, J.A. Priming of pathogenesis related-proteins and enzymes related to oxidative stress by plant growth promoting rhizobacteria on rice plants upon abiotic and biotic stress challenge. J. Plant Physiol. 2015, 188, 72-79, doi:10.1016/j.jplph.2015.09.011.

15. Baker, N.R. Chlorophyll fluorescence: A probe of photosynthesis in vivo. Annu. Rev. Plant Biol. 2008, 59, 89-113, doi:10.1146/annurev.arplant.59.032607.092759.

16. Bi fai, P.; Grant, A.; Reid, B. Chlorophyll a fluorescence as a biomarker for rapid toxicity assessment. Envirom. Toxicol. Chem. 2007, 26, 1520-1531, doi:10.1897/06-394R1.1.

17. Guetsky, R.; Kobiler, I.; Wang, X.; Perlman, N.; Gollop, N.; Avila-Quezada, G.; Hadar, I.; Prusky, D. Metabolism of the flavonoid epicatechin by laccase of Colletotrichum gloeosporioides and its effect on pathogenicity on avocado fruits. Phytopatholoy 2005, 11, 1341-1348, doi:10.1094/PHYTO-95-1341.

18. Galleotti, F.; Barile, E.; Curir, P.; Dolci, M.; Lanzotti, V. Flavonoids from carnation (Dianthus caryophyllus) and their antifungal activity. Phytochem. Lett. 2008, 1, 44-48, doi:10.1016/j.phytol.2007.10.001.

19. Manach, C.; Williamson, G.; Morand, C.; Scalbert, A.; Remesy, C. Bioavailability and bioefficacy of polyphenols in humans. I. Review of 97 bioavailability studies. AJCN 2005, 81, 230S-242S, doi:10.1093/ajen/81.1.230S.

Publisher's Note: MDPI stays neutral with regard to jurisdictional claims in published maps and institutional affiliations.

(C) 2020 by the authors. Submitted for possible open access publication under the terms and conditions of the Creative Commons Attribution (CC BY) license (http://creativecommons.org/licenses/by/4.0/). 